\title{
Moving beyond evidence-free environmental policy
}

\author{
Jeremy Russell-Smith ${ }^{1,2 *}$, David Lindenmayer ${ }^{2,3}$, Ida Kubiszewski ${ }^{4}$, Peter Green ${ }^{2,5}$, Robert Costanza ${ }^{4}$, \\ and Andrew Campbell ${ }^{1}$
}

Despite universal recognition that environmental policy should be informed by robust scientific evidence, this is frequently (and perhaps increasingly) not the case, even in wealthy countries such as Australia. How can the scientific community respond to this fundamental problem? While acknowledging that many constructive actions can be taken, and that scientists have a direct responsibility to inform the policy-making process and advocate for sound policy positions, we contend that such responses are insufficient unless the wider community is better informed and engaged. We agree with those who believe that a broader democratization of the policy-making process is essential to improving this situation, and that an expanded application of scenario planning, augmented with targeted public-opinion surveys, has considerable potential. Used in this way, scenario planning can help scientists engage with and inform citizens about the kind of world they want to live in, while incorporating the best science about possible futures.

Front Ecol Environ 2015; 13(8): 441-448, doi:10.1890/150019

$\mathrm{I}$ t seems obvious that the development and implementation of environmental policy should be based on the best available scientific evidence. However, such evidence is often highly uncertain and inherently contestable. Balancing diverse scientific information input poses serious challenges to policy makers even where broad scientific consensus has been reached, for example where multilateral governance agreements address complex issues such as global climate change (UNFCCC 1998) or sus-

\section{In a nutshell:}

- There is a growing tendency for policy makers to dismiss or ignore scientific advice when making environmental decisions - how should the scientific community respond to this challenge?

- While there are many constructive actions that could be taken, we suggest that in democratic societies the wider community needs to be better informed and empowered if decision making on difficult environmental issues is to improve

- Here, we focus on engaging the broader community in expanded scenario-planning exercises, including testing community preferences in targeted public surveys

- This expanded approach is mostly untested to date but offers considerable promise for informing the environmental policy development process

\footnotetext{
${ }^{1}$ Darwin Centre for Bushfire Research, Research Institute for the Environment and Livelihoods, Charles Darwin University, Darwin, Australia *(jeremy.russell-smith@cdu.edu.au); ${ }^{2}$ Long Term Ecological Research Network, Australian National University, Canberra, Australia; ${ }^{3}$ Fenner School of Environment and Society, Australian National University, Canberra, Australia; ${ }^{4}$ Crawford School of Public Policy, Australian National University, Canberra, Australia; ${ }^{5}$ Department of Ecology, Environment and Evolution, La Trobe University Bundoora, Melbourne, Australia
}

tainable harvesting of marine resources (Neubauer et al. 2013). The nature of evidence itself is often contested, especially in situations where policy debates involve different or competing value systems (Oreskes 2004; Pielke 2007; Adams and Sandbrook 2013). How scientists should properly and effectively engage with such debates for instance, to either independently advise policy makers or publicly advocate for certain policies and political outcomes - are matters addressed in the literature of many disciplines (eg biodiversity conservation, health, and international development).

Even more perplexing are situations where the scientific evidence base is attacked or ignored for ideological reasons, or because it threatens powerful vested interests. The cover of a recent edition of National Geographic (March 2015) simply describes the affront as "the war on science". There is an apparent trend, particularly in wealthy liberal democracies of the English-speaking world (notably Australia, Canada, and the US), to ignore or overlook scientific evidence on important environmental issues, and even to defund or abolish independent sources of scientific advice. Well-known cases include failures to account for projected climate-change impacts in approving major fossil-fuel developments; unsustainable exploitation of marine fisheries and tropical forests; over-allocation of groundwater resources; and developments in low-lying coastal regions that ignore projected rises in sea level (see WebTable 1 for examples specific to Australia).

Turner (2013) argued compellingly that the Canadian Government has, over the past several years, mounted a systematic attack on science and scientists in order to facilitate rapid resource extraction. Turner further contended that scientific input to policy development has been marginalized systematically in three different ways by reducing the government's capacity to gather data, by 


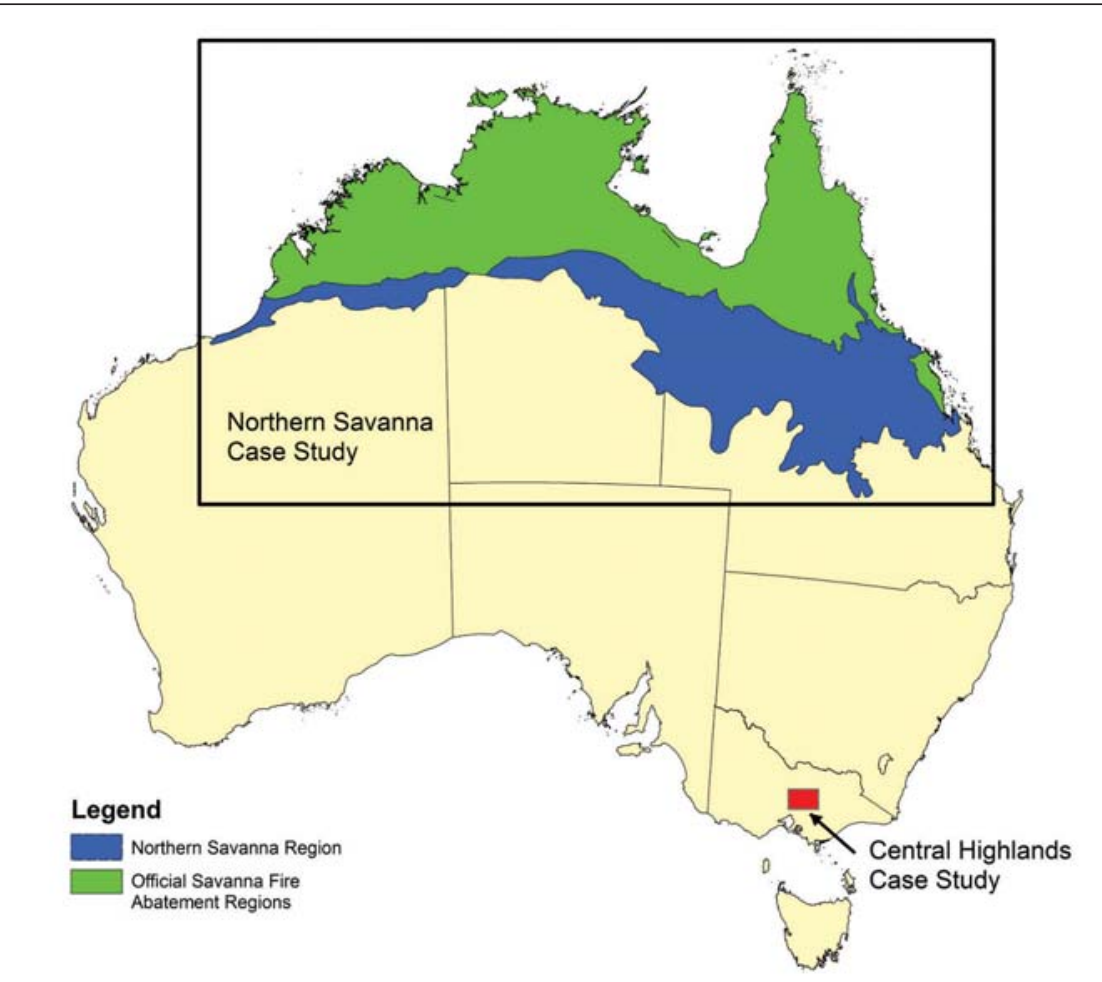

Figure 1. Location of the northern savannas and central Victorian highlands case studies. Extensive (free-range) cattle production is the primary land use in the northern savannas region (Fox et al. 2001). However, much of the savannas are relatively unsuitable for cattle farming, while "carbon farming", especially when paired with improved fire management (green area; Whitehead et al. 2014), offers new economic opportunities.

defunding or abolishing independent sources of scientific advice, and by censoring communication between scientists and stakeholders. Many commentators have made similar observations regarding climate-change policy in the US (http://bit.ly/WGtp5a) and in Australia (http:// bit.ly/1UnDHiU; http://bit.ly/1UnDSuI).

How should the scientific community respond to this challenge to evidence-based policy? Potential actions include: promoting independent review of policies; supporting the scientific education of legislators and mainstream media; fostering a closer dialogue on policy issues with the business community (beyond interaction regarding commercial technologies and innovation); and encouraging community participation through online discussion, citizen science, and activism. However, as noted by commentators who focus on the nexus between science inputs, policy formulation, and political action, there is often a tacit assumption by many in the scientific community that simply getting the science "right" is an adequate prerequisite for political action. In most instances - but especially for complex issues - policy development is probably not a linear process, but is demonstrably fuzzy, creative, contested, and multifactorial (Pielke 2007; Adams and Sandbrook 2013).
We would argue that the typical science advocacy responses are necessary but insufficient unless the broader community is better informed and engaged. We describe two examples of recurring Australian development myths, and consider how to inform and empower communities to influence participatory, evidence-based decision-making processes - illustrated here with reference to application of expanded scenario-planning tools augmented with public-opinion surveys.

\section{Australian environmental policy that ignores scientific evidence}

Australia is well-positioned to tackle environmental problems effectively. It enjoys a rich environmental science expertise (Harrison 2006), mature institutional capability, high relative wealth and corruption-free governance, and a public sector with the capacity and professed willingness to incorporate scientific input into evidence-based policy formulation (Australian Government 2012). Yet denial of scientific evidence is abundantly apparent in Australia, exemplified here by two contemporary examples (Figure 1) with far-reaching development implications.

\section{Northern development}

Both the conservative and progressive sides of Australian politics have developed policies that pledge to "develop the north", and specifically to develop "the northern food bowl", a recurring aspiration since the early days of European settlement in the 1800 s. There is a political perception that because the savanna landscapes of northern Australia are extensive $\left(\sim 2\right.$ million $\left.\mathrm{km}^{2}\right)$ and sparsely populated $\left(0.3\right.$ persons $\left.\mathrm{km}^{-2}\right)$, and contain seasonally plentiful water near the coast, the region is ripe for development (Australian Government 2015). Such claims are usually accompanied by points about the burgeoning demand for protein from the growing middle class of Asian countries, and suggestions that agricultural production in the established food-growing regions of southeastern Australia is constrained by water scarcity, a limitation that is being amplified by climate change.

However, there is ample scientific evidence to suggest that the potential for agricultural development in northern Australia is severely limited. Evaporation generally exceeds annual rainfall, and the flat topography prevents 

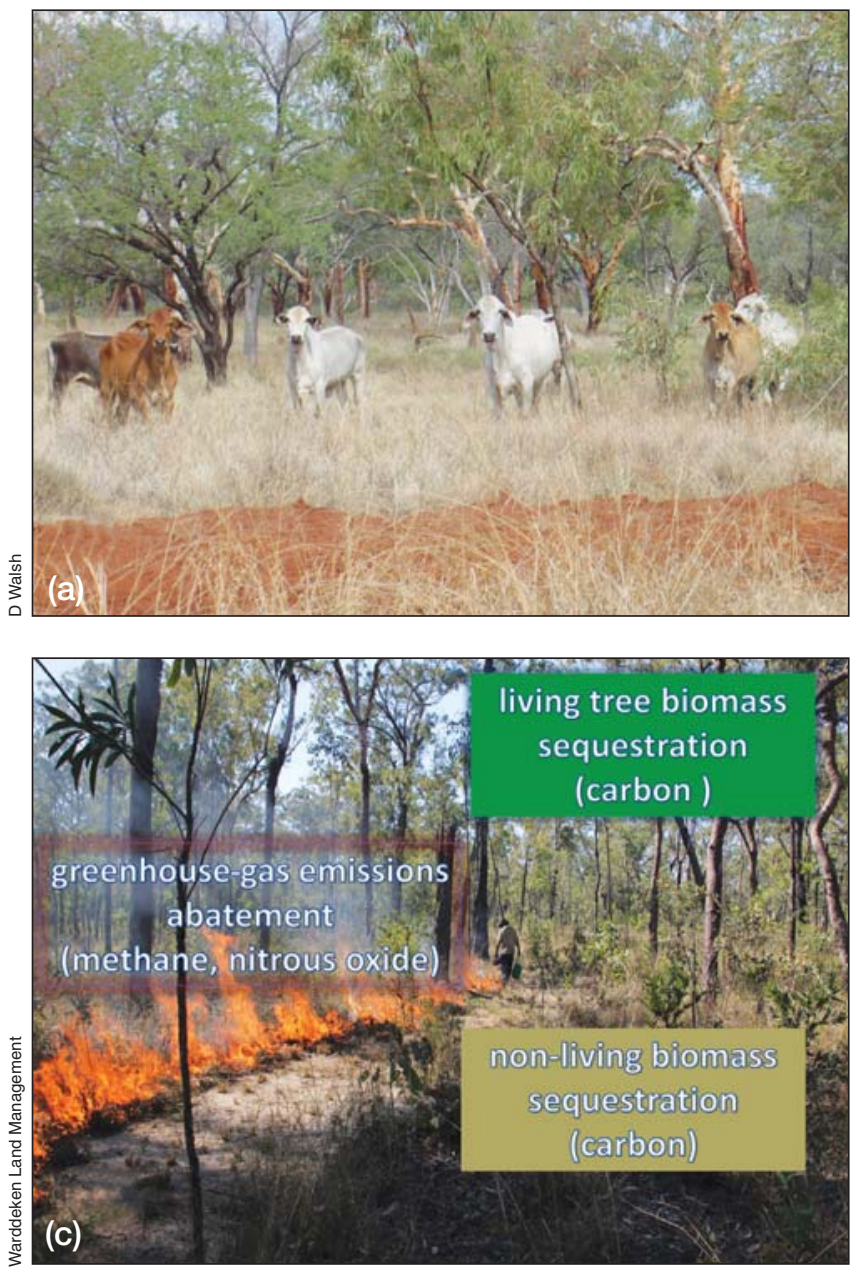

water storage. As much as $90 \%$ of the northern savannas are used ostensibly for beef cattle pastoralism - largely under extensive (as opposed to intensive, irrigated, or grain-fed) production systems (Figure 2a). Industry reports show that most northern pastoral enterprises are neither economically viable nor sustainable (McLean et al. 2014) due to low-fertility soils, seasonal access restrictions, limited infrastructure, high labor and input costs, and distant and volatile markets. Mining and energy extraction industries are major contributors to the regional economy, but are limited to restricted onshore and offshore development sites, and exhibit "boom-bust" cycles driven by volatile global commodity markets and fluctuating prices.

Aspirations for a "northern food bowl" and associated agricultural development were first comprehensively debunked by Bruce Davidson (1965) in his critical economic analysis, The northern myth. More recently, authoritative assessments have reinforced the view that the potential for large-scale irrigable agriculture is very limited (Figure 2b). The Northern Australia Land and Water Taskforce (NALWT 2009) estimated that the potential for growth in irrigable land is only two or three times the area currently under production - with a maximum of 40000 ha. There is also some relatively small potential for "mosaic irrigation", based on localized groundwater resources

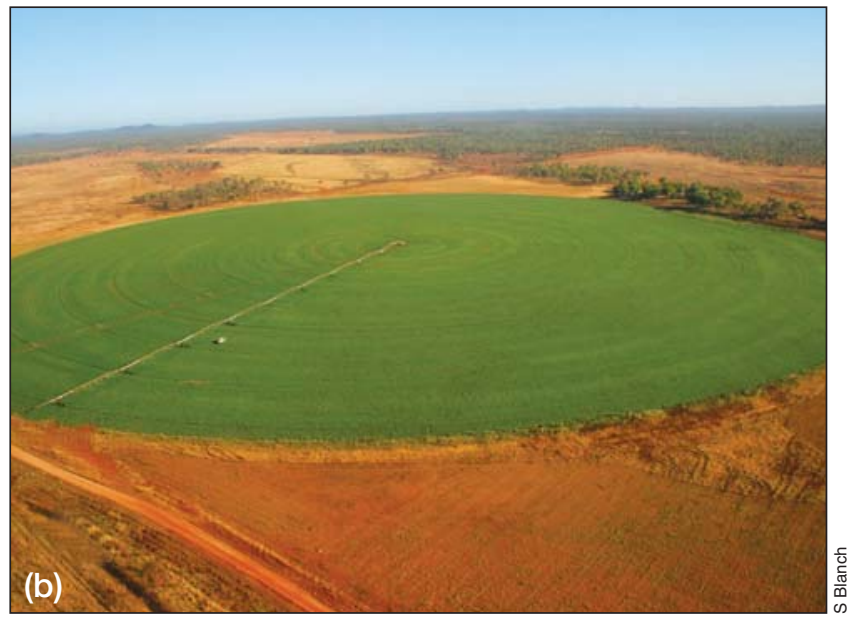

Figure 2. Land-use options in Australia's northern savannas: (a) free-range Bos indicus cattle production, restricted by extensive infertile, laterized (deeply chemically weathered) soils; (b) irrigated agriculture (including center-pivot irrigation of peanuts), restricted by limited aquifers and seasonal water availability; (c) carbon farming (greenhouse-gas emissions abatement; sequestration into non-living and living biomass components) through improved fire management over extensive regions of fire-prone northern savannas.

(Petheram et al. 2013a, 2013b). In comparison, the total agricultural area irrigated in Australia's Murray-Darling Basin in 2010-2011 was 1.2 million ha (Australian Bureau of Statistics 2013). Furthermore, large irrigation projects in the north would require enormous, non-redeemable public expenditure on infrastructure, and might be more viable if used for non-food crops that do not require refrigeration, such as cotton, sugarcane, and sandalwood (NALWT 2009; Petheram et al. 2013a, 2013b).

Such development options have little support among many of the Indigenous (Aboriginal) residents who comprise the majority of the non-urban, regional population and who own much of the land under either freehold title or non-exclusive title arrangements, yet are mostly impoverished. Although some Indigenous savanna residents, particularly those with educational and training qualifications, may take up mainstream employment opportunities (eg in the mining, tourism, health, education, defense, and pastoral sectors), many others, particularly in remote communities, fulfill other priorities, including cultural responsibilities for "looking after [the] country" (Altman and Kerins 2012).

The northern savannas are highly fire-prone, providing options for both rural Indigenous residents and pastoralists to develop diversified "carbon farming" enterprises, especially through improved fire management activities (Figure 2c; Russell-Smith et al. 2013; Walsh et al. 2014). However, given the apparent fixation of Australian governments on pursuing limited visions of northern agricultural development, opportunities for north Australia's rural residents to engage in decision- 


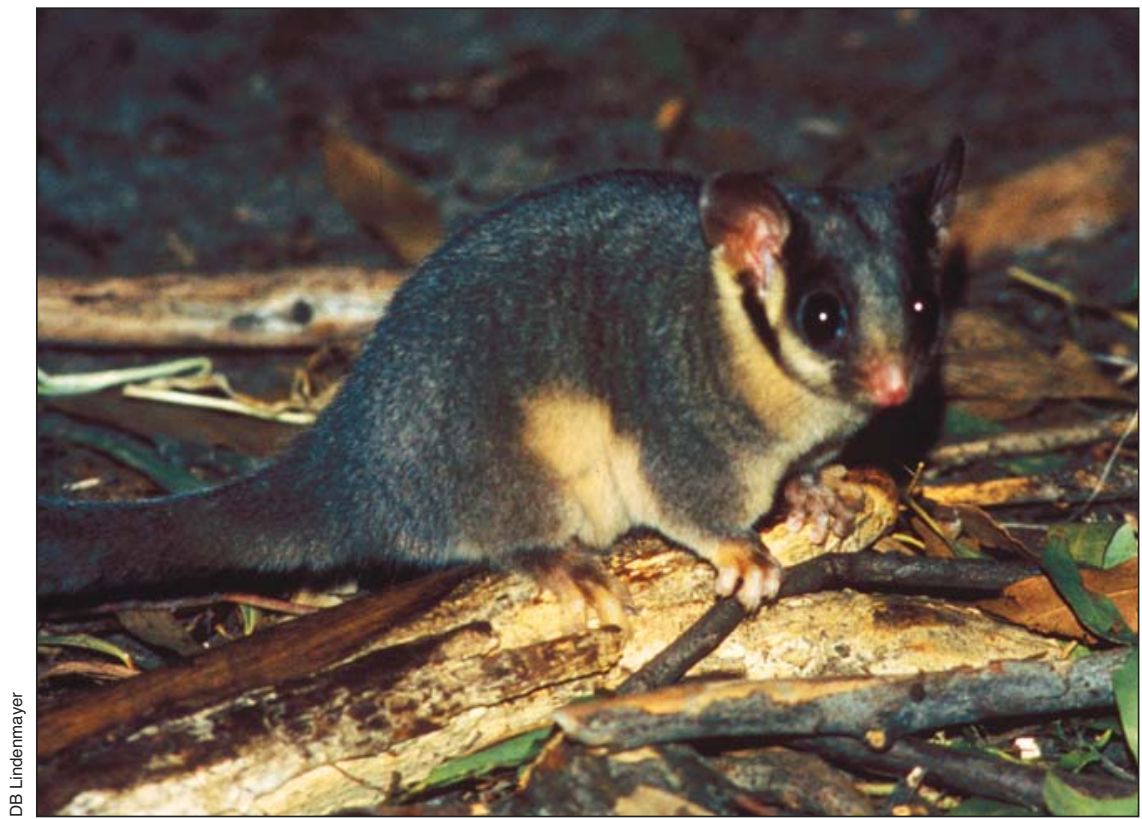

Figure 3. Leadbeater's possum (Gymnobelideus leadbeateri).

making processes that might deliver more culturally and environmentally appropriate forms of development are limited and dwindling.

\section{Alpine and mountain ash forest logging in Victoria}

The tall eucalypt mountain ash (Eucalyptus regnans) and alpine ash (Eucalyptus delegatensis) forests of Victoria are some of the world's most spectacular forests, with oldgrowth stands containing the tallest flowering plants on Earth. These ecosystems provide much of the water for the city of Melbourne (Viggers et al. 2013), are some of the most carbon-dense forests worldwide (Keith et al. 2009), and support habitat for endangered species such as Leadbeater's possum (Gymnobelideus leadbeateri; Figure 3; Lindenmayer et al. 2013).

These mountain ash and alpine ash forests are among the most extensively studied ecosystems, both in Australia and globally (Lindenmayer 2009). However, the scientific knowledge accumulated through these studies is not reflected in regional forest management policies, particularly those concerning biodiversity conservation and fire policy and management.

For instance, it has been well established for more than 20 years that widespread clearcut logging operations in mountain ash forests substantially degrade the suitability of forest habitats for Leadbeater's possum and up to 40 other species of vertebrates that are dependent on large, old, cavity-bearing trees (Figure 4; Lindenmayer 1994). Moreover, since the 2009 wildfires - which destroyed $\sim 43 \%$ of habitat for Leadbeater's possum - controls on logging have been loosened rather than strengthened (Lindenmayer and Possingham 2013). Government policies purportedly attempting to conserve the possum have failed to incorporate recommendations for improved management based on three decades of science (Lindenmayer et al. 2014), and are likely to have negative impacts on the species.

A further example relates to relationships between logging and wildfire. The mountain ash and alpine ash forests in Victoria are subject to rare but catastrophic high-severity fires, the intensity of which is strongly linked to weather. Recent analyses indicate that fire severity is also related to logging history and is greatly elevated in stands of forest 7-40 years after logging (Taylor et al. 2014). This means that the $\sim 7100$ ha of forest that has been clearcut and regenerated in the past four decades is at risk of high-severity fire. Moreover, a further 17655 ha of forest is scheduled to be clearcut in the coming 5 years under the Victorian Government's Timber Release Plan (Government of Victoria 2011). Large areas of fire-prone young forest are close to towns and settlements, which are therefore at risk from high-severity wildfire. Yet, to date there has been no attempt by the Government of Victoria to mitigate fire risks in regional towns by curtailing clearcutting in nearby forested areas.

Finally, despite the large areas of mountain ash and alpine ash forest logged in the past four decades and the extensive areas of forest burned in the 2009 fires (Burns et al. 2014), the Government of Victoria has made only limited attempts to reduce the amount of harvesting pressure on the forest estate. This means that the rate of cutting of the smaller remaining areas of unburned "green" forest has actually increased. It is not possible to claim that these problems are unknown or poorly understood. The status of mountain ash forests following the 2009 wildfires is well documented, as is the biology and ecology of the organisms of conservation concern inhabiting those forests. Stands of trees old enough to be sawlogs (felled tree trunks, suitable for timber) may well be exhausted within the coming 10-15 years, leading to the possible removal of the sawlog industry from the Central Highlands region. Despite this, the policy position of the Victorian Government is set to "lock in" 20-year guaranteed wood supplies from public forests to the forest industry (Victorian Department of Primary Industries 2011), even though there may be insufficient timber resources to do this.

The likely result of "locking in" pulpwood and timber supplies will be to ensure the extinction of iconic species such as Leadbeater's possum, as well as the sawlog sector of the forest industry, and compromise other "new century industries" such as managing native forests for carbon stores (Keith et al. 2014) and for the provision of other ecosystem services such as water supply and recreation. Thus, policy and management do not match either the conservation sci- 
Figure 4. The various stages of clearcutting in montane ash forests: (a) sellable trees are cut, leaving dead stems and debris; (b) debris is burned in a high-intensity regeneration fire; (c) the burned site is then artificially regenerated with the new crop of trees.

ence or the resource (ie ecosystem services, including wood supply) science. The wider community needs to be both better informed about development options and more empowered to contribute to the decision-making process.

\section{How can scientists contribute to improved environmental decision making?}

Clearly, scientists can and should continue to build the weight of evidence on issues through their core activity of undertaking rigorous, high-quality research, and publishing in peer-reviewed academic journals. Researchers should also continue to make scientific evidence and its interpretation more accessible to all stakeholders, scientists and non-scientists alike. This already happens in many different ways, but considerable progress could still be made on two fronts. First, the assembly of policy-neutral, systematic reviews of evidence should be expanded, perhaps along similar lines to those of the Cochrane Collaboration in the healthcare sector (www.cochrane.org; see Bilotta et al. 2014). Reviews such as these are already being made publicly available through organizations like the Collaboration for Environmental Evidence (www.environmentalevidence.org), the US's Union of Concerned Scientists (www.ucsusa.org), and the European Network of Scientists for Social and Environmental Responsibility (www.ensser.org). Second, there are growing calls for scientists to collaborate with knowledge brokers to transform scientific narratives into community dialogues as a way of effectively communicating knowledge and influencing public policy (Mauz et al. 2012). Citizen-science initiatives potentially expand the participation base and the audience for such community dialogues.

These and other, similar ideas are not novel, but they have yet to be systematically applied to the process of assembling and assessing scientific evidence for complex public-policy challenges. We recognize that scientific advice is just one kind of input to policy formulation (Head 2008), and can be trumped by ideology and vested interests (WebTable 1). Other approaches are needed that permit, encourage, and sustain broader, informed community engagement and consensus building.

\section{Enhanced scenario planning with public-opinion surveys as part of the solution}

Solving complex problems requires an adequate understanding of both how the system in question works and a vision of shared goals for the system among stakeholders (Costanza 2001). The lack of a shared vision and goals is one important reason why scientific evidence may be ignored in management and policy. Goals such as pro-
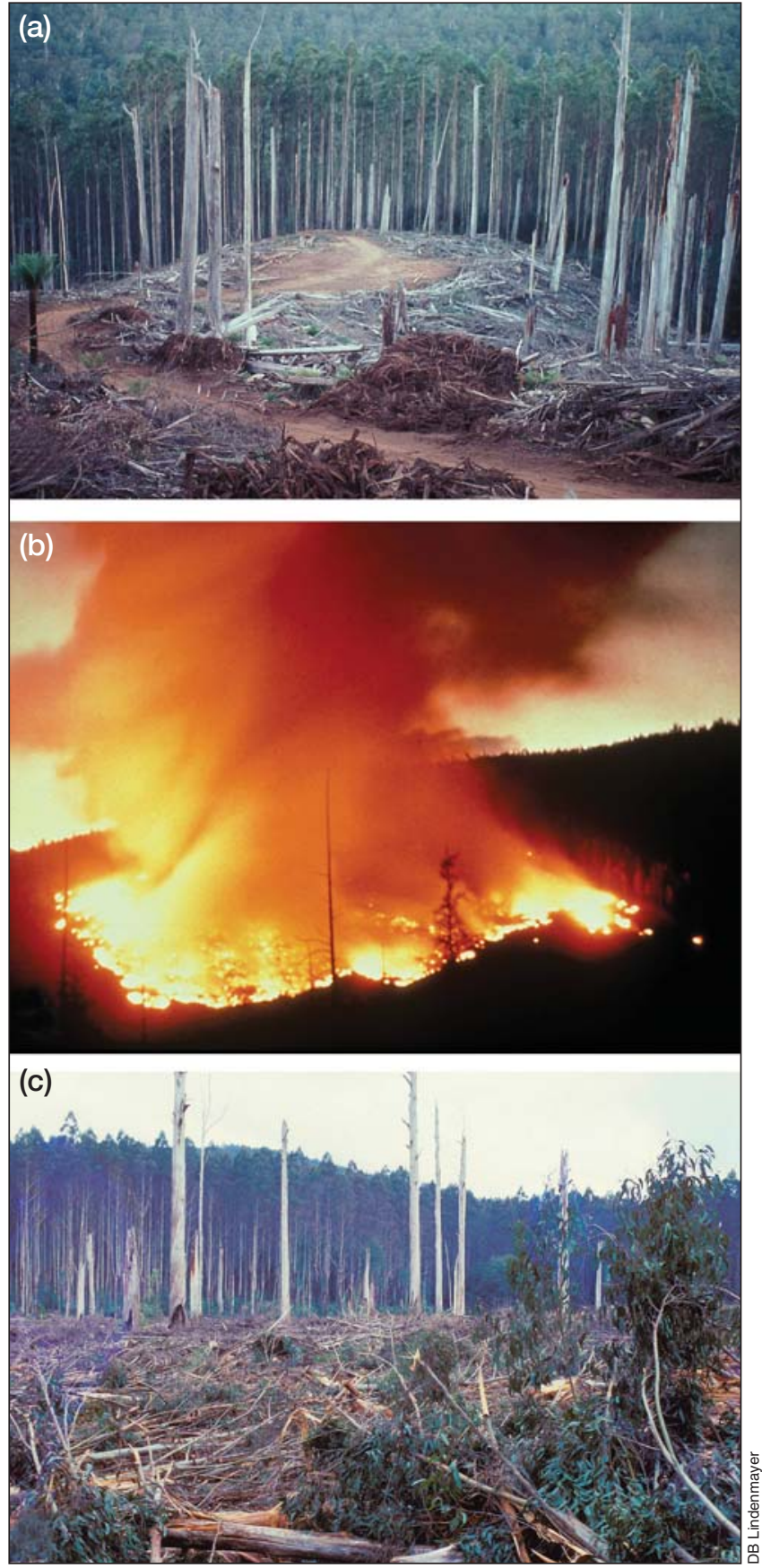

moting the "northern food bowl", or continuing past harvesting practices in Victoria while maintaining minimal environmental and social impacts, are not consistent with possibilities for the region or the ideas of other important stakeholders. Such policies are inherently unsustainable and, more importantly, ignore or discount competing views for alternative futures for these distinctive regions and do not adequately engage the public in the process of goal creation.

We argue that a broadly shared vision about the world we want to live in, informed by the best available science, provides a better platform for sound policy development. In essence, this is what democratic governance should do. 
Unfortunately, current versions of democracy give too much weight to powerful special-interest groups (Gilens and Page 2014) whose visions and goals are not consistent with those of the broader public, including the scientific community. One of the consequences of the anti-climate science movement - particularly in the English-speaking world - is to paint science as just another interest group, with a vested interest in exaggerating problems to increase research budgets.

Scenario planning (Ringland and Schwartz 1998; Peterson et al. 2003) is one tool that can help to build a shared vision. Scenario planning differs from forecasts, projections, and predictions in that it explores plausible rather than probable futures (Peterson et al. 2003). Although aspects of the depicted futures may come to exist, these futures are best viewed as caricatures of reality, which we can use to learn from and to build consensus.

Scenario planning is based on four assumptions: that (1) the future is unlike the past, and is extensively shaped by human choice and action; (2) the future cannot be foreseen, but exploring possible futures can inform present decisions; (3) there are many possible futures, and so scenarios lie within a "possibility space"; and (4) scenario development involves both rational analysis and creative thinking (TFP 2003).

Scenarios are best suited to exploring situations of high uncertainty and low controllability (Peterson et al. 2003). For example, climate change and global governance are largely beyond the control of a particular region. In these situations, scenarios can help to illuminate the consequences of these uncontrollable forces and to formulate robust local responses. Importantly, scenarios can help to reveal policy and value changes that may be required, and identify critical decision points where such changes can most strongly affect outcomes (Gallopín 2002).

How could scenario planning be applied to northern development and the clearcutting of ash forests in Victoria in ways that will help to build a shared vision that engages the public? Scenario planning itself is certainly not new, but using scenarios as the basis for broad public-opinion surveys and discussion has not been done before. As in most scenario-planning exercises, representatives of major stakeholder groups should collaborate to envision plausible futures for these areas. The resulting scenarios would cover the full range of options, from business-as-usual development to more sustainable approaches. In all cases, the scenarios must be "plausible", meaning that they should take scientific evidence into account and combine rational analysis and creative thinking.

Scenario planning, even in contentious situations, can bring stakeholders together to consider options for the whole system (Kahane 2004). It allows participants to step out of their special-interest mode and begin to develop shared ideas. Scenario planning is now embedded in the strategic thinking of some of the world's most influential institutions, including the World Bank and United Nations Environment Programme. This approach was also used in the Millennium Ecosystem Assessment to chart possible trajectories for the global community, based on the rate and extent of ecological change and interactions with management policies (MA 2005). Scenario planning need not be static; scenarios can be revisited and reworked as part of a longterm formal process: for example, the iterative application of scenario planning to guide water management in the Netherlands since the 1950s (Haasnoot and Middelkoop 2012).

Once a range of scenarios is created, a consensus often emerges among participants as to which options are most desirable, given underlying uncertainties about the future. For example, a scenario-planning process in South Africa involving all political parties developed four scenarios for the country's transition out of apartheid (Kahane 2004). The "flight of the flamingos" scenario, which imagines both black and white South Africans rising up together, emerged as the clear consensus and led to the Truth and Reconciliation Committee and other strategies that allowed a relatively peaceful and cooperative transition in a situation that might have otherwise become even more violent and repressive. The development of an evidence-based understanding of how the world works, combined with a shared vision of how people want it to work, are powerful tools to address even the most complex and recalcitrant of problems.

Another example of a strategic scenario-planning exercise focused on the future of the food system and was undertaken by Chatham House (2008), an independent policy institute. This policy research project explored the effects of global trends on the networks that supply wheat and dairy products to the UK market. The exercise drew from a core panel of stakeholders representing a wide cross-section of different sectors within the food system, informed by researchers from many institutions across the UK. It identified critical variables associated with oil prices, food stocks, and prevailing economic conditions, and developed four very different but internally coherent scenarios for the evolution of the British food supply system. The highly participatory nature of the exercise - from the cabinet strategy office to industry leaders and representatives of leading NGOs and consumer organizations - meant that the research was informing public and private policy development well before it was finally published. Policy development on this complex, long-term issue was seen to be necessarily a shared enterprise between government, industry, and civil society.

However, to move beyond the environmental policymaking problems discussed above requires that scenarios developed by "expert" stakeholder representatives be shared and used in a much broader context, to meaningfully engage the public in the debate. 
Building on scenario planning to identify preferred futures

To take the process of empowerment to its logical conclusion, we contend that scenarios should be used as the basis for broad public-opinion surveys (Costanza 2000; Costanza et al. 2015). Although such sampling of public opinion around future scenarios - as far as we are aware has been limited, an instructive example is provided by the designers of an online scenario game for exploring futures in New Zealand (LRSWG 2007). Several hundred game participants provided feedback on the scenario situation they considered New Zealand to be in now, where they would like the country to be in 50 years, and where they thought the country was actually heading. While most respondents sought a future characterized by greater environmental sustainability and social cohesion, they perceived the country to be heading in the opposite direction.

The inexorable spread of the internet and rising familiarity with online survey instruments and engagement tools have created a basis for developing new approaches to informing, engaging, and consulting the community in developing more sustainable approaches to environmental management and making difficult resource-allocation decisions. Such approaches could combine strategic scenario-planning exercises with online sharing of data and analyses. Subsequent well-targeted surveys would inform citizens about complex and contested issues, and improve the chances of policy decisions being based on sound scientific evidence.

\section{Conclusion}

We have attempted to identify useful approaches for scientists to engage with the policy development process, particularly in instances where compelling evidence continues to be ignored due to differing ideologies or vested interests. While science advocacy is both useful and necessary (Kassen 2011), we concur with arguments advanced by Pielke (2007) and Adams and Sandbrook (2013) that the "honest broker" role of scientists in complex political debates (even where the science may seem straightforward) should be to inform, guide, and expand the options available to policy makers, rather than to advocate for specific, prescriptive solutions. Given inherent long-term potential for scientists to be perceived as yet another interest group in support of certain lines of evidence (and research funding), we advocate for a broader democratization of the policy-making process. To do this requires much more active public engagement in the process of coming to consensus about the future we all want and overcoming special-interest biases. Scenarioplanning exercises augmented with well-constructed and targeted public-opinion surveys of those scenarios have considerable, but untested, potential for helping us to make more prudent decisions about our collective future.
This approach can incorporate the best scientific evidence in a way the public can understand and could help to build the shared vision necessary to truly serve the public interest.

\section{References}

Adams WM and Sandbrook C. 2013. Conservation, evidence and policy. Oryx 47: 329-35.

Altman J and Kerins S (Eds). 2012. People on country: vital landscapes, Indigenous futures. Sydney, Australia: The Federation Press.

Australian Bureau of Statistics. 2013. Water use on Australian farms, 2010-11. www.abs.gov.au/ausstats/abs@.nsf/Lookup/ 4618.0main+features52010-11. Viewed 19 Aug 2014.

Australian Government. 2015. Our north, our future: white paper on developing Northern Australia. http://northernaustralia. infrastructure.gov.au/white-paper/index.aspx. Viewed 4 Aug 2015.

Australian Government. 2012. APS 200 Project: the place of science in policy development in the public service. www.industry.gov.au/science/Pages/APS200ProjectSciencein Policy.aspx. Viewed 19 Aug 2014.

Bilotta GS, Milner AM, and Booyd I. 2014. On the use of systematic reviews to inform environmental policies. Environ Sci Policy 42: 67-77.

Burns E, Lindenmayer DB, Stein JA, et al. 2014. Ecosystem assessment of mountain ash forest in the Central Highlands of Victoria, south-eastern Australia. Austral Ecol 40: 386-99.

Chatham House. 2008. Thinking about the future of food: The Chatham House food supply scenarios. London, UK: Chatham House Food Supply Project, Royal Institute of International Affairs, Chatham House. https://www.chathamhouse.org/ sites/files/chathamhouse/public/Research/Global\%20Trends/ bp0508food.pdf. Viewed 4 Aug 2015.

Costanza R. 2000. Visions of alternative (unpredictable) futures and their use in policy analysis. Conserv Ecol 4: 5 .

Costanza R. 2001. Visions, values, valuation and the need for an ecological economics. BioScience 51: 459-68.

Costanza R, Kubiszewski I, Cork S, et al. 2015. Scenarios for Australia in 2050: a synthesis and proposed survey. J Futures Studies 19: 49-76.

Davidson BR. 1965. The northern myth. Melbourne, Australia: Melbourne University Press.

Fox ID, Neldner VJ, Wilson GW, and Bannink PJ. 2001. The vegetation of the tropical Australian savannas. Brisbane, Australia: Environment Protection Agency.

Gallopín GC. 2002. Planning for resilience: scenarios, surprises and branch points. In: Gunderson L and Holling CS (Eds). Panarchy: understanding transformations in human and natural systems. Washington, DC: Island Press.

Gilens M and Page BI. 2014. Testing theories of American politics: elites, interest groups, and average citizens. Perspectives on Politics 12: 564-81.

Government of Victoria. 2011. Timber release plan 2011-2016. Melbourne, Australia: Government of Victoria.

Haasnoot M and Middelkoop H. 2012. A history of futures: a review of scenario use in water policy in the Netherlands. Environ Sci Policy 19/20: 108-20.

Harrison AL. 2006. Who's who in Conservation Biology - an authorship analysis. Conserv Biol 20: 652-57.

Head BW. 2008. Three lenses of evidence-based policy. Aust J Publ Admin 67: 1-11.

Kahane A. 2004. Solving tough problems: an open way of talking, listening, and creating new realities. San Francisco, CA: Berrett-Koehler.

Kassen R. 2011. If you want to win the game, you must join in. Nature 480: 153. 
Keith H, Mackey BG, and Lindenmayer DB. 2009. Re-evaluation of forest biomass carbon stocks and lessons from the world's most carbon-dense forests. P Natl Acad Sci USA 106: 11635-40.

Keith H, Lindenmayer DB, Mackey BG, et al. 2014. Managing temperate forests for carbon storage: impacts of logging versus forest protection on carbon stocks. Ecosphere 5; doi:10.1890/ ES14-00051.1.

Lindenmayer DB. 1994. The impacts of timber harvesting on arboreal marsupials at different spatial scales and its implications for ecologically sustainable forest use and nature conservation. Aust J Environ Manage 1: 56-68.

Lindenmayer DB. 2009. Forest pattern and ecological process: a synthesis of 25 years of research. Melbourne, Australia: CSIRO Publishing.

Lindenmayer DB and Possingham HP. 2013. No excuse for habitat destruction. Science 340: 680.

Lindenmayer DB, Blanchard W, McBurney L, et al. 2013. Fire severity and landscape context effects on arboreal marsupials. Biol Conserv 167: 137-48.

Lindenmayer DB, Blair D, McBurney L, et al. 2014. Principles and practices for biodiversity conservation and restoration forestry: a 30 year case study on the Victorian montane ash forests and the critically endangered Leadbeater's possum. Aust Zool 36 441-60.

LRSWG (Landcare Research Scenarios Working Group). 2007. Work in progress: four scenarios for New Zealand (2nd edn). Lincoln, New Zealand: Manaaki Whenua Press.

MA (Millennium Ecosystem Assessment). 2005. Ecosystems and human well-being: synthesis. Washington, DC: Island Press.

Mauz I, Peltola T, Granjou C, et al. 2012. How scientific visions matter: insights from three long-term socio-ecological research (LTSER) platforms under construction in Europe. Environ Sci Policy 19/20: 90-99.

McLean I, Holmes P, and Counsell D. 2014. The Northern beef report. 2013 Northern beef situation analysis. Project B.COM.0348. North Sydney, Australia: Meat \& Livestock Australia.

NALWT (Northern Australia Land and Water Taskforce). 2009. Sustainable development of northern Australia. Canberra, Australia: Department of Infrastructure, Transport, Regional Development and Local Government. http://regional.gov. au/regional/ona/files/NLAW.pdf. Viewed 4 Aug 2015.

Neubauer P, Jensen OP, Hutchings JA, and Baum JK. 2013. Resilience and recovery of overexploited marine populations. Science 340: 347-49.

Oreskes N. 2004. Science and public policy: what's proof got to do with it? Environ Sci Policy 7: 369-83.

Peterson GD, Cumming G, and Carpenter SR. 2003. Scenario planning: a tool for conservation in an uncertain world. Conserv Biol 17: 358-66.

Petheram C, Watson I, and Stone P (Eds). 2013a. Agricultural resource assessment for the Gilbert catchment. A report to the Australian Government from the CSIRO Flinders and Gilbert Agricultural Resource Assessment, part of the North Queensland Irrigated Agriculture Strategy. Canberra, Australia: CSIRO Water for a Healthy Country and Sustainable Agriculture flagships.

Petheram C, Watson I, and Stone P (Eds). 2013b. Agricultural resource assessment for the Flinders catchment. A report to the Australian Government from the CSIRO Flinders and Gilbert Agricultural Resource Assessment, part of the North Queensland Irrigated Agriculture Strategy. Canberra, Australia: CSIRO Water for a Healthy Country and Sustainable Agriculture flagships.

Pielke RA Jr. 2007. The honest broker: making sense of science in policy and politics. Cambridge, UK: Cambridge University Press.

Ringland G and Schwartz P. 1998. Scenario planning: managing for the future. New York, NY: John Wiley and Sons.

Russell-Smith J, Cook GD, Cooke PM, et al. 2013. Managing fire regimes in north Australian savannas: applying customary Aboriginal approaches to contemporary global problems. Front Ecol Environ 11: e55-e63.

Taylor C, McCarthy MA, and Lindenmayer DB. 2014. Fire severity in relation to forest age: evidence from south-east Australia. Conserv Lett; doi:10.1111/conl.12122.

TFP (Technology Foresight Program). 2003. Foresight futures 2020: revised scenarios and guidance. London, UK: Foresight.

Turner C. 2013. The war on science: muzzled scientists and willful blindness in Stephen Harper's Canada. Vancouver, Canada: Greystone Books Limited.

UNFCCC (United Nations Framework Convention on Climate Change). 1998. Kyoto Protocol to the United Nations Framework Convention on Climate Change. http://unfccc. int/kyoto protocol/items/2830.php. Viewed 1 Apr 2015.

Victorian Department of Primary Industries. 2011. Timber Industry Action Plan. Melbourne, Australia: Government of Victoria.

Viggers JI, Weaver HJ, and Lindenmayer DB. 2013. Melbourne's water catchments: perspectives on a world-class water supply. Melbourne, Australia: CSIRO Publishing.

Walsh D, Russell-Smith J, and Cowley R. 2014. Fire and carbon management in a diversified rangelands economy: research, policy and implementation challenges. Rangeland J 36: 313-22.

Whitehead PJ, Russell-Smith J, and Yates CP. 2014. Carbon markets and improved management of fire in north Australian savannas: identifying sites for productive targeting of emissions reductions. Rangeland J 36: 371-88. 